\title{
The haemolytic activity of an iron carbohydrate complex
}

\author{
J. FIELDING
}

with the technical assistance of

\author{
GILLIAN M. SMITH
}

From Paddington General Hospital, London

SYNOPSIS The haemolytic activity of iron-dextran complex is found to be a function of time, $\stackrel{\vec{N}}{\circ}$ temperature, $p \mathrm{H}$, and concentration. The lytic action is enhanced by small amounts of added ferrous sulphate. The lytic action is inhibited by chelating agents such as citrate and sequestrene salts, which $\bar{c}$ bind ionic iron, but not by ferric citrate or ferric sequestrene which do not bind iron. The ionised iron content of iron-dextran is deduced.

The lytic activity of iron-dextran is also inhibited by iron-dextrin and by an iron-sorbitol-citric acid preparation. It is suggested that the iron-sorbitol-citrate molecular complex contains free $\mathscr{E}_{\omega}$ chelating groups for iron.

The significance of these findings for iron-carbohydrate toxicity and metabolism is brieflyo discussed.

The clinical toxicity of parenteral iron preparations, both intravenous and intramuscular, has been one of the principal problems associated with their use. The toxic manifcstations are varied in kind and tend to form a pattern of reactions characteristic in type for each iron complex.

It is unlikely that a single factor is responsible for all or even most of the observed toxic reactions. Instability of the complex in plasma with possible precipitation in vivo is a likely cause in the case of the saccharated oxide but improbable with the dextran, dextrin, or sorbitol complexes. The rate of reticulo-endothelial uptake from the circulation, the rate of release of dissociated iron from reticuloendothelial cells, dissociation of the complex in the circulation, the intrinsic ionic iron content of the complex, and anaphylactic phenomena have all been postulated. It is clear that each complex needs to be considered separately in detail.

The firm bond between ferric hydroxide and the carbohydrates, from which iron carbohydrate complexes are synthesized, simulates to some extent the binding of inorganic iron to transferrin. The iron in these complexes is almost entirely non-ionized and in consequence comparatively large amounts are tolerated in the circulation without toxic effect. ConReceived for publication 7 July 1962. centrations of $4 \mathrm{mg}$. iron per $100 \mathrm{ml}$. as iron-dextrin or iron-dextran are regularly achieved during treatment; this is 50 times the normal concentration of $\frac{3}{2}$ iron in the circulation. After the administration of an iron carbohydrate complex the degree of saturation of the iron-binding capacity rises. The time at which용 this occurs also varies with the complex: with saccharated iron-oxide it occurs during the first few hours, with iron-dextrin after three hours, with iron- $\delta$ dextran after two or three days, but with iron- $₹$ sorbitol it is immediate, returning to normal in 20 윽 hours. It appears that all these complexes contain or yield up at some stage diffusible or ionized iron which combines with transferrin. Klopper (1951) N suggested that when transferrin was fully saturated excess ionized iron manifested itself in toxic re- $N$ actions. This is an attractive hypothesis and one which is widely quoted. There have, however, been 0 no reports of the state of transferrin saturation during ${ }_{0}$ the actual occurrence of toxic reactions. On the other $\frac{}{\Phi}$ hand, it may be shown that after injections of iron $\stackrel{\oplus}{+}$ sorbitol transferrin may be fully saturated without 70 toxic reaction.

Nissim (1954) in a study of toxicity measured $\stackrel{\mathbb{D}}{\overparen{D}}$ several properties, including haemolytic activity of $\frac{\vec{D}}{\mathrm{O}}$ saccharated iron oxide and some other iron compounds. The haemolytic action was assessed by the 
comparatively crude technique of direct microscopic observation. Golberg (1958) suggested that haemolytic activity may be a measure of the presence of free ferric ion and therefore an index of toxicity. The dark colour and viscosity of iron carbohydrate complexes make measurement of the haemolytic action by conventional haemoglobin measurements difficult and inaccurate but a red cell counting technique using an electronic blood cell counter enables the haemolytic activity of such solutions to be measured simply and accurately (Fielding, 1961). A report is given here of some experimental observations on the haemolytic activity of iron-dextran and its relationship to ionized iron.

\section{METHODS AND MATERIALS}

HAEMOLYSIS Red cell lysis is measured by a cell-counting technique using an EEL electronic blood cell counter. To $4 \mathrm{ml}$. volumes of fluid under test, is added $0.02 \mathrm{ml}$. of a three times washed suspension of human red cells in saline. After incubation the unlysed cells are enumerated in four $0.2 \mathrm{ml}$. volumes and the mean taken: thus for an original suspension of 5 million red cells per c.mm. 20,000 red cells are counted. The difference in count from a saline control suspension is taken as the measure of haemolysis. Differences of less than $\pm 3 \%$ are ignored.

STANDARD IRON-DEXTRAN HAEMOLYSIS When the effects of various factors on iron-dextran haemolysis had been ascertained as described below, conditions were standardized thus: final concentration of iron-dextran, $5 \mathrm{mg}$. Fe per $\mathrm{ml}$.; washed red cell suspension, 3.5 to 6.0 million cells per c.mm.; incubation, six hours at $37^{\circ} \mathrm{C}$.

References in the text to iron carbohydrate concentration refer to the concentration of elemental iron.

Iron-dextran was used as Imferon (Benger) and irondextrin and iron-sorbitol were used as Astrafer and Jectofer (Astra-Hewlett) respectively.

Sorensen's phosphate buffers were prepared from $M / 15$ disodium hydrogen phosphate and $M / 15$ sodium dihydrogen phosphate. To $100 \mathrm{ml}$. of each $p \mathrm{H}$ mixture, $8 \mathrm{~g}$. sodium chloride was added and the solution diluted 1 in 10 to bring it to normal osmolarity.

McIlvaine's citric acid-phosphate buffers were prepared from $M / 5$ disodium hydrogen phosphate and $M / 10$ citric acid. To $100 \mathrm{ml}$. of each $p \mathrm{H}$ mixture, $6 \mathrm{~g}$. sodium chloride was added and the solution diluted 1 in 10 . These buffered salines were tested for haemolytic action before use.

\section{RESULTS}

IRON-DEXTRAN, IRON-DEXTRIN, AND IRON-SORBITOL Figure 1 shows the haemolysis produced by varying concentrations of iron-dextran in six hours at $37^{\circ} \mathrm{C}$., whereas iron-dextrin and iron-sorbitol produce no haemolysis, as previously reported (Golberg, 1958; Lindvall and Andersson, 1961; Fielding, 1961).

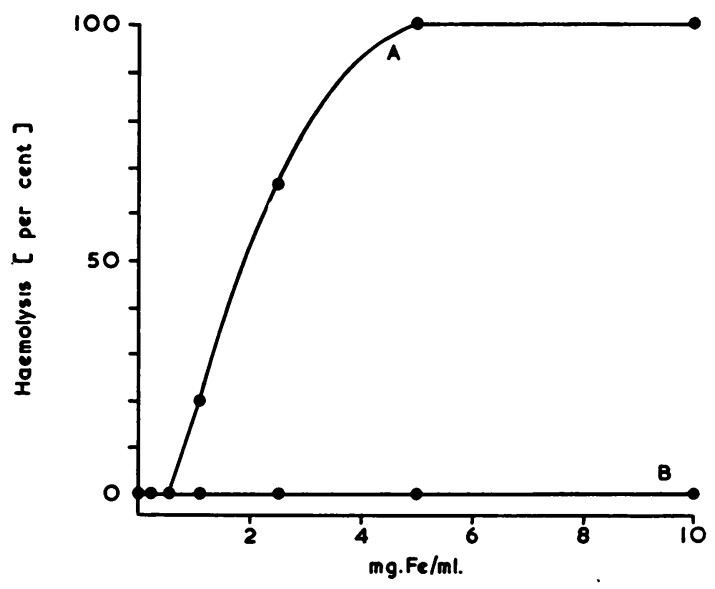

FIG. 1. Iron-dextran $(A)$, iron-dextrin $(B)$, and ironsorbitol $(B)$. Abscissa = concentration of iron complex as elemental iron. Red cell suspension 4,580 per $0.2 \mathrm{ml}$.; incubation six $\mathrm{hr} .137^{\circ} \mathrm{C}$.

CONCENTRATION OF IRON-DEXTRAN The rate of irondextran haemolysis increases with concentration (Fig. 2). At a concentration of $0.5 \%$, haemolysis is complete in six hours at $37^{\circ} \mathrm{C}$. The reciprocal of the time taken for $50 \%$ haemolysis varies approximately with the logarithm of the concentration.

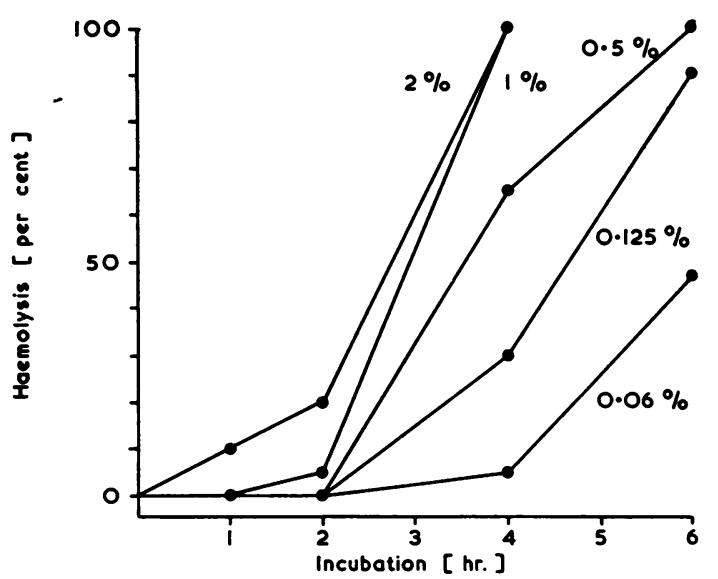

FIG. 2. Effect of iron-dextran concentrations, $0.06 \%$ to $2.0 \% \mathrm{Fe}$, on the rate of haemolysis at $37^{\circ} \mathrm{C}$.

EFFECT OF TEMPERATURE Figure 3 shows the rate of haemolysis produced by $0.5 \%$ iron-dextran at $37^{\circ} \mathrm{C}$., at room temperature, and at $4{ }^{\circ} \mathrm{C}$. At all temperatures there is a latent period of about two hours before perceptible haemolysis is observed, after which the rate of haemolysis increases with temperature. At $37^{\circ} \mathrm{C}$. haemolysis is complete in six hours; 


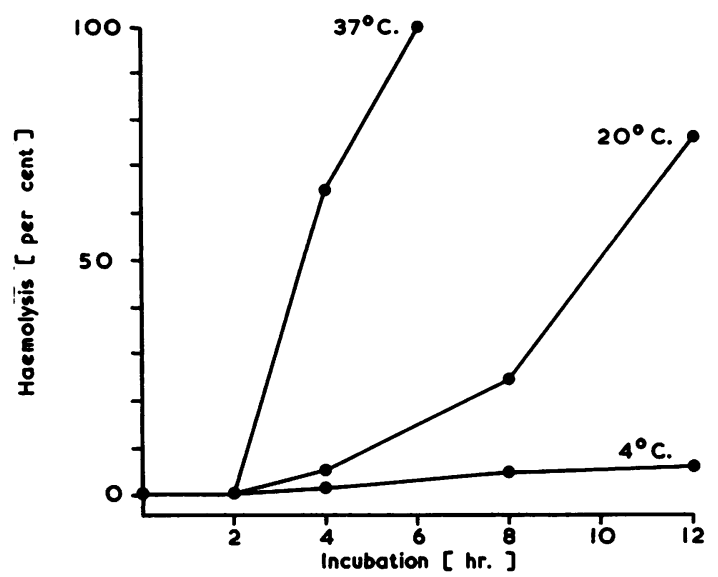

FIG. 3. Effect of temperature on $0.5 \%$ iron-dextran haemolysis. Red cell suspension, 6,200 per $0.2 \mathrm{ml}$.

at $4^{\circ} \mathrm{C}$. little haemolysis takes place in the first 12 hours, although by 24 hours it is complete. This temperature effect contrasts with osmotic haemolysis in which the rate of haemolysis does not vary perceptibly in this temperature range.

EFFECT OF $p H$ Iron-dextran was diluted serially in doubling dilutions through isotonic Sorensen's buffers, and tested for haemolytic activity at $37^{\circ} \mathrm{C}$. for six hours.

Table I shows that haemolytic activity increases with increasing acidity at all concentrations of irondextran. At $p \mathrm{H} 8$ a concentration of $0.5 \%$ is inactive
but at $p \mathrm{H} 5.4$ haemolysis is virtually complete.

Iron-dextrin and iron-sorbitol were also tested in the range $p \mathrm{H} 5.4$ to 8 at concentrations varying from $0.06 \%$ to $1.0 \% \mathrm{Fe}$, and again no haemolytic activity was observed.

EFFECT OF ETHYLENE DIAMINE TETRA-ACETIC ACID SALTS Sodium, potassium, and calcium sequestrene क salts chelate iron, that is, they bind iron in non- $\vec{O}$ ionized form, giving up their own metallic radicals. If iron-dextran haemolysis is due to its content of ionized iron it should therefore be inhibited in the presence of such chelating agents. Table II shows the results of varying concentrations of potassium, cal- $\vec{P}$ cium, and iron sequestrenes on the haemolytic acti- $\overrightarrow{.}$ vity of $0.5 \%$ iron-dextran. Both the potassium and $\vec{N}$ the calcium salts neutralize the lytic effect of the iron- $\frac{\text { ? }}{2}$ carbohydrate complex. Ferric sequestrene, which $\rightarrow$ cannot bind inorganic iron, has no effect on the haemolytic action. This supports the view that irondextran haemolysis is due to its content of ionized iron. The concentration of sequestrene required to $\overrightarrow{ }$ inhibit haemolytic activity is small: $M / 320$ of either $\stackrel{\circ}{\circ}$ potassium or calcium salt completely inhibits haemolysis, and concentrations down to $2 \mathrm{M} \times 10^{-4}$ exert perceptible inhibitory effects.

EFFECT OF ORGANIC SALTS ON IRON-DEXTRAN HAEMOLYSIS The chelating action of sequestrene salts is $\stackrel{\Phi}{\circ}$ well known. The citrate ion also has a capacity to $\overrightarrow{\vec{O}}$ chelate metals and this is, of course, the basis of the 3

TABLE I

HAEMOLYTIC ACTIVITY OF IRON-DEXTRAN

\begin{tabular}{|c|c|c|c|c|c|c|c|}
\hline \multirow[t]{2}{*}{$p \mathbf{H}$} & \multicolumn{7}{|c|}{ Concentration of Iron-dextran (Fe g. per $100 \mathrm{ml}$.) } \\
\hline & $2 \cdot 0$ & $1 \cdot 0$ & $0 \cdot 5$ & 0.25 & $0 \cdot 125$ & 0.06 & 0.03 \\
\hline $\begin{array}{l}5 \cdot 4 \\
6 \\
7 \\
8\end{array}$ & $\begin{array}{r}90 \\
20 \\
160 \\
70\end{array}$ & $\begin{array}{r}80 \\
80 \\
580 \\
3,180\end{array}$ & $\begin{array}{r}290 \\
990 \\
3,840 \\
4,150\end{array}$ & $\begin{array}{l}1,160 \\
3,000 \\
4,160 \\
4,180\end{array}$ & $\begin{array}{l}2,250 \\
3,990 \\
4,190\end{array}$ & $\begin{array}{l}4,010 \\
4,020\end{array}$ & 3,950 \\
\hline
\end{tabular}

Red cell counts per $0.2 \mathrm{ml}$. Incubation six hr. $/ 37^{\circ} \mathrm{C}$.

TABLE II

ACTION OF SEQUESTRENE SALTS ON $0.5 \%$ IRON-DEXTRAN HAEMOLYSIS

Final Dilution of $M / 10$ Sequestrene Salt

\begin{tabular}{|c|c|c|c|c|c|c|c|c|c|c|c|}
\hline & \multirow{2}{*}{\multicolumn{9}{|c|}{$0.5 \% \mathrm{Fe}$ as Iron-dextran }} & \multirow{2}{*}{\multicolumn{2}{|c|}{ No Iron Dextran }} \\
\hline & & & & & & & & & & & \\
\hline & $1 / 8$ & $1 / 16$ & $1 / 32$ & $1 / 64$ & $1 / 128$ & $1 / 256$ & $1 / 512$ & $1 / 1,024$ & $1 / 2,048$ & $1 / 8$ & $1 / 2,048$ \\
\hline $\begin{array}{l}\text { KaE.D.T.A. } \\
\text { CaE.D.T.A. } \\
\text { FeNa,E.D.T.A. }\end{array}$ & $\begin{array}{r}5,550 \\
5,640 \\
190\end{array}$ & $\begin{array}{r}5,600 \\
5,650 \\
230\end{array}$ & $\begin{array}{r}5,580 \\
5,380 \\
210\end{array}$ & $\begin{array}{r}3,330 \\
4,890 \\
190\end{array}$ & $\begin{array}{r}1,300 \\
980 \\
180\end{array}$ & $\begin{array}{r}760 \\
550 \\
90\end{array}$ & $\begin{array}{l}230 \\
220 \\
100\end{array}$ & $\begin{array}{r}120 \\
90 \\
120\end{array}$ & $\begin{array}{l}40 \\
50 \\
40\end{array}$ & $\begin{array}{l}5,520 \\
5,620 \\
5,200\end{array}$ & $\begin{array}{l}5,490 \\
5,630 \\
5,240\end{array}$ \\
\hline
\end{tabular}

Red cell counts per $0.2 \mathrm{ml}$. after six hr. $/ 37^{\circ} \mathrm{C}$. in $0.5 \%$ iron dextran.

Initial count in saline 5,570 per $0.2 \mathrm{ml}$. 
anticoagulant action of citrates. Sodium citrate has a similar action on inorganic iron as it has on calcium, and might therefore be expected to have an inhibitory action on iron-dextran haemolysis similar to that of sequestrene salts. The effect of sodium citrate and ferric citrate was therefore investigated in the same way as that of sequestrene salts. Calcium citrate is too insoluble to be tested.

Ferric citrate was without effect. Sodium and potassium citrates were found to have marked inhibitory actions on iron-dextran haemolysis. These salts are, however, strongly alkaline and it was possible therefore that their actions were due to changes in $p \mathrm{H}$. To test this possibility, isotonic McIlvaine's citric acid-phosphate buffers at $p \mathrm{H} \mathrm{5.4}$ and $p \mathrm{H} 6$ were serially diluted through Sorensen's phosphate buffers at similar $p \mathrm{H}$ levels. The resulting buffered isotonic mixtures gave two series at a constant $p \mathrm{H}$, in which the only significant variable was a serial two-fold dilution of citric acid.

When the haemolytic activity of $0.5 \%$ iron dextran was tested in these buffers, complete inhibition of lysis resulted in the presence of $\mathrm{M} / 640$ citric acid at $p \mathrm{H} 5.4$ and $\mathrm{M} / 2560$ at $p \mathrm{H} \mathrm{6.0}$. Thus the citrate effect was not due to $p \mathrm{H}$ change alone, but was evidently the result of the ionic iron-binding capacity of the citrate ion.

A number of other organic and inorganic sodium salts were also tested for inhibitory action on irondextran haemolysis. Sodium sulphate, lactate, and salicylate were without effect. Sodium oxalate, fumarate, succinate, fluoride, and cyanide shared varying degrees of protective action. Sodium benzo- ate and acetate could not be tested since they are haemolytic alone.

The effects of citrate, succinate, and oxalate are shown in Fig. 4, which also includes the action of the sequestrene salts for comparison. The action of sodium citrate is particularly well marked, a concentration of $M / 1280$ giving complete inhibition of $0.5 \%$ iron-dextran haemolysis.

EFFECT OF IRON-DEXTRIN AND IRON-SORBITOL ON IRON-DEXTRAN HAEMOLYSIS As shown above neither iron-dextrin nor iron-sorbitol have haemolytic activity. Both complexes in the form used here are known to contain citrate and it therefore seemed possible that their citrate content might account for their lack of lytic activity. Furthermore, it seemed possible that these preparations might exhibit chelating activity towards inorganic iron. They were therefore tested in the same way as the sequestrene and citrate salts.

Both complexes showed marked protective effects against iron-dextran haemolysis, the sorbitol complex being more effective than the dextrin (Fig. 5). A dilution of 1 in 80 iron-sorbitol $(0.62 \mathrm{mg}$. Fe per ml.) exerts the same protective effect as $M / 1,280$ sodium citrate. If it is assumed that the whole of the protective effect is due to the citrate content of the complex, the original undiluted iron-sorbitol complex $(5.0 \%$ Fe) would contain $M / 16$ citrate, which corresponds to $12 \mathrm{mg}$. citric acid per millilitre. It has been shown by continuous flow electrophoresis of iron-sorbitol that the citric acid content moves in two fractions, corresponding to the two main iron fractions in the complex. The total citric acid thus revealed is

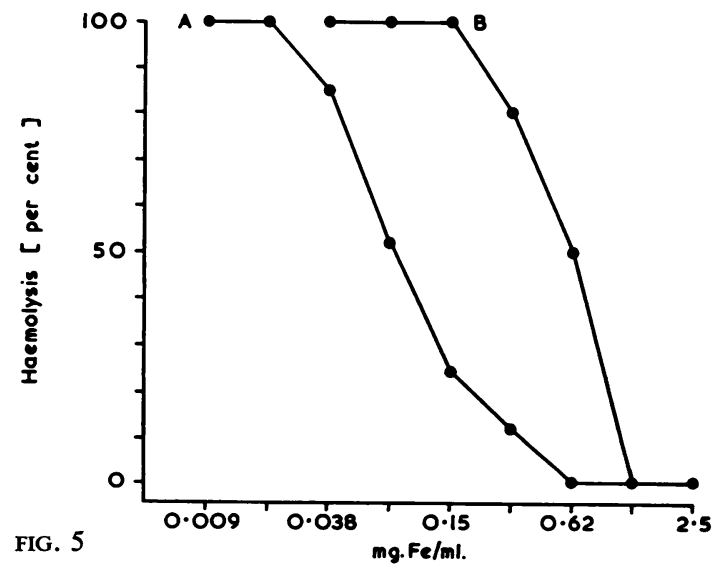

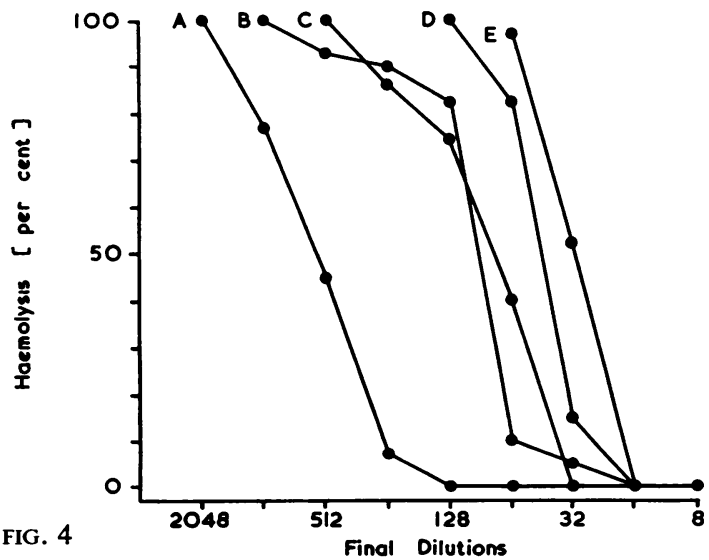

FIG. 4. Inhibition of $0.5 \%$ iron-dextran haemolysis, six $\mathrm{hr} .137^{\circ} \mathrm{C}$. Abscissa $=$ final dilution of $\mathrm{M} / 10$ salts of $\mathrm{A}$, sodium citrate; B, CaE.D.T.A.; C, $K_{2}$ E.D.T.A.; D, sodium succinate; E, sodium oxalate.

FIG. 5. Inhibition of $0.5 \%$ iron-dextran haemolysis, six $\mathrm{hr} .137^{\circ} \mathrm{C}$. Abscissa $=$ final concentration of added ironsorbitol $(A)$ or iron-dextrin $(B)$. 
approximately $31 \mathrm{mg}$. per millilitre. It seems likely, therefore, that part of the citrate content of ironsorbitol (as Jectofer) determines the non-haemolytic character of iron-sorbitol. No similar data are available for iron-dextrin, but since it is also known to contain citrate, similar considerations may apply.

EFFECT OF IRON SALTS ON RED CELLS If it is accepted that the ionized iron content of iron-dextran causes haemolysis, a similar direct action of ionized iron in the form of inorganic salts might be expected. Since inorganic ferric salts are strongly acid in solution and cause acid haemolysis, the action of the ferric ion in this form cannot be ascertained. On the other hand, the chelated ferric organic salts, such as ferric citrate and ferric sequestrene, should have no direct haemolytic or agglutinating action on red cells, and this was found to be so.

Freshly prepared solutions of ferrous sulphate made up to isotonic strength with saline have an agglutinating action on red cells, without haemolysis. The agglutination produced by weak concentrations is easily broken up by shaking and the cells may be counted. Ferrous sulphate agglutination is inhibited by the presence of sodium and calcium sequestrene and by sodium citrate, but not by ferric sequestrene or ferric citrate. Table III illustrates the effect of calcium sequestrene. Thus ferrous sulphate agglutination is inhibited by the same agents as inhibit iron-dextran haemolysis.

EFFECT OF FERROUS SULPHATE ON IRON-DEXTRAN HAEMOLYSIS The evidence that iron-dextran haemolysis is due to ionized iron is thus far indirect and based on the inhibitory effects of chelating salts. Furthermore, ionic iron as ferrous sulphate exhibits only agglutination without haemolysis. It seemed possible that the agglutination by ferrous sulphate might be modified in the presence of the large ironcomplex molecule.

The effect of adding small amounts of ferrous sulphate to iron-dextran was therefore tested. Table IV shows that ferrous sulphate increases the haemolytic titre of iron-dextran. This haemolysis is also inhibited by sequestrene salts and by citrate.

By measuring the inhibition titre of calcium sequestrene on iron-dextran haemolysis with and without added ferrous sulphate, the haemolytic equivalent of iron-dextran in terms of ferrous sulphate may be calculated. From such an evaluation it appeared that iron-dextran (as Imferon) contains the equivalent of $\mathrm{N} / 200$ ferrous sulphate. A similar titration, using sodium citrate as inhibitor, gives the equivalent value of $\mathrm{N} / 160$ ferrous sulphate. Thus this preparation of iron-dextran, which contains $5 \%$ elemental iron, contains between $0.014 \%$ and $0.023 \%$ ionized iron, that is, about $1 / 300$ th part of the iron present is ionized.

\section{DISCUSSION}

The experiments described demonstrate that irondextran (Imferon) has a haemolytic action which is a function of $p \mathrm{H}$, concentration, temperature, and time. This haemolysis is inhibited by potassium and calcium sequestrenes but not by ferric sequestrene. It is also inhibited by some sodium salts, such as

TABLE III

AGGLUTINATING ACTION OF FeSO ${ }_{4}$ AND ITS INHIBITION BY

CaE.D.T.A.

\begin{tabular}{lllllllll}
$3 \mathrm{ml}$. Dilutions of $\mathrm{M} / 300$ & $\mathrm{FeSO}_{4}$ & \\
\cline { 2 - 7 } & $1 / 4$ & $1 / 8$ & $1 / 16$ & $1 / 32$ & $1 / 64$ & $1 / 128$ & $1 / 256$ & $1 / 512$ \\
\hline
\end{tabular}

Plus $1 \mathrm{ml}$. saline

Plus $1 \mathrm{ml}$. M/160 CaE.D.T.A.

$+++$

$\div:+\quad: \div+t++$

$+\div$

$10^{6}$ cells $/ \mathrm{c} . \mathrm{mm}$

TABLE IV

INTERACTION OF IRON-DEXTRAN HAEMOLYSIS AND FERROUS SULPHATE AGGLUTINATION

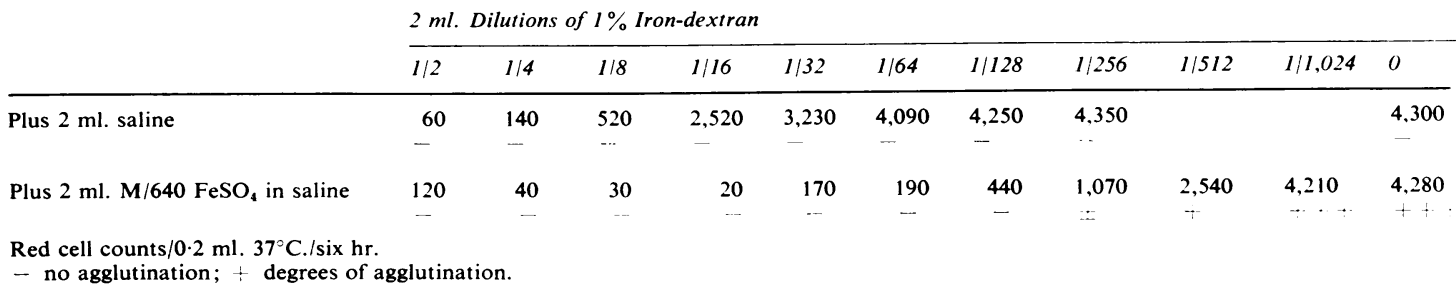

- no agglutination; + degrees of agglutination. 
citrate, lactate, and fumarate, which form poorly ionized iron compounds, but not by ferric citrate.

Haemolysis is thus inhibited by iron-binding chelating agents but not by ferric sequestrene or ferric citrate which cannot bind iron. Small amounts of ferrous sulphate added to iron-dextran increase the haemolytic titre and this increased activity is also inhibited by chelating agents. Ferrous sulphate alone has an agglutinating but no haemolytic action on red cells, which is also inhibited by the same reagents. It appears, therefore, that in the presence of the large molecule of the iron-dextran complex the agglutinating action of ferrous sulphate becomes a haemolytic one. These results support the hypothesis that iron-dextran haemolysis is due to its content of ionized iron. It should be noted that the concentrations required for haemolysis in vitro are not attained in vivo during therapy.

As measured by the inhibitory effect of calcium sequestrene and of sodium citrate, iron-dextran, which contains $5 \% \mathrm{w} / \mathrm{v}$ elemental iron, contains the equivalent of $0.014 \%$ to $0.023 \%$ ferrous iron. Thus about 1/300th part of the iron content of Imferon is ionized. Assuming therefore that the haemolytic action of iron-dextran is due entirely to its content of ionized iron, $5 \mathrm{ml}$. Imferon $(=250 \mathrm{mg}$. Fe) contains at the most $1 \mathrm{mg}$. ionic iron. This is far short of the amount required to saturate transferrin ironbinding capacity, and the ionized content of this complex cannot therefore account for the toxic effects sometimes observed soon after intravenous injection in man.

Since both iron-dextrin and iron-sorbitol have neither agglutinating nor haemolytic action over a wide range of $p \mathrm{H}$ and concentration, it appears that they contain no free ionic iron. On the contrary, they appear to contain an excess of chelating bonds, since they are both capable of neutralizing the haemolytic effect of iron-dextran in the same way as chelating salts. If it is assumed that the anti-haemolytic activity is due solely to citrate, the activity may be expressed as a citric acid concentration, and amounts in the case of iron-sorbitol to $12 \mathrm{mg}$. per $\mathrm{ml}$.

Analysis of iron-sorbitol (as Jectofer) by continuous flow electrophoresis (Lindvall, 1962) shows that its citric acid content is about $31 \mathrm{mg}$. per ml., and moves in two fractions corresponding to two iron fractions. The minor fast-moving fraction is dialysable, and its citric acid content is about $13 \mathrm{mg}$. per $\mathrm{ml}$. In this fraction, iron and citric acid are present in equivalent proportions, and it is therefore unlikely that the citric acid in this fraction is capable of binding further iron. Thus the anti-haemolytic activity may reside in the larger, slow-moving, nondialysable fraction, consisting of iron-sorbitol-citric acid of mean molecular weight about 5000. The citric acid content of this fraction amounts to about $18 \mathrm{mg}$. per ml.

Laurell (1951), in discussing the physiological transfer of iron from the vascular to the extravascular and cellular compartments, shows that transferrin does not leave the circulation, and postulates that iron enters cells as a relatively small molecular weight complex after dissociation from transferrin. Charley, Rosenstein, Shore, and Saltman (1960) have shown that chelating agents, such as citrate and E.D.T.A., enhance the uptake of iron from serum transferrin by rat liver slices and homogenates. They suggest that naturally occurring low molecular weight chelators are active in the movement of iron out of the circulation from transferrin to tissue receptors. It is possible, therefore, that low molecular weight chelated iron, permeable to capillary endothelium, may have important physiological functions. If this were so, it could be anticipated that the utilization of the iron-sorbitol-citric acid complex, which contains its iron in this form and remains capable of binding further ionic iron, would follow different and perhaps more physiological pathways than nondiffusible iron complexes of high molecular weight.

The present results suggest that the view of iron carbohydrate toxicity, which considers only the release of ionic iron and the saturation of transferrin. is probably too simple a picture. The availability of chelating bonds other than transferrin may well modify the status of iron in the circulation, and it becomes possible to visualize transferrin saturation without necessarily incurring the risk of ionic toxicity.

\section{REFERENCES}

Charley, P., Rosenstein, M., Shore, E., and Saltman, P. (1960).Arch. Biochem., 88, 222

Fielding, J. (1961). Brit. med. J., 2, 279.

Golberg, L. (1958). In Iron in Clinical Medicine, edited by R. O. Wallerstein and S. R. Mettier, p. 77. Univ. California Press, Berkeley.

Klopper, A. (1951). Lancet, 1, 531.

Laurell, C. B. (1951). Blood, 6, 183.

Lindvall, S. (1962). Personal communication.

-, and Andersson, N. S. E. (1961). Brit. J. Pharmacol., 17, 358.

Nissim, J. A. (1954). Ibid., 9, 103. 